\title{
Espeita Ramisa, M. T. (2015). José Espeita García-Arista, pasión por la música (Historia de una vocación musical). Barcelona: Artyplan, 291 pp. ISBN: 978-84-608-1870-0.
}

A día de hoy, aún son muchos los nombres de grandes músicos que, a pesar de haber desempeñado un visible y decisivo lugar en la sociedad de su tiempo, no han sido incluidos en la historiografía. Una de esas figuras es el protagonista del volumen titulado José Espeita García-Arista: pasión por la música (Historia de una vocación musical) escrito por María Teresa Espeita Ramisa (2015).

Se trata de un libro de carácter biográfico destinado a dar a conocer a José Espeita García-Arista (1912-2002), un músico polifacético y desconocido para el gran público actual que desarrolló una activa labor en la composición musical, la docencia, la dirección y la escritura, entre otros de los múltiples campos que abordó y que son presentados en el volumen que nos atañe. Su autora, María Teresa Espeita Ramisa, hija del protagonita, realiza un profundo estudio en el que se presenta, de forma objetiva con la revisión de los hechos históricos que rodearon a su protagonista, a una persona cuya vida estuvo plenamente dedicada a la música y a la cultura.

De entrada, conviene señalar que este libro no es un mero estudio biográfico, de aquellos que en el siglo XIX habrían estado repletos de datos anecdóticos sin consistencia, sino que la autora, de una forma magistral, enmarca a Espeita García-Arista en la realidad sociocultural de la Barcelona de su época. Ello es expuesto en un trabajo caracterizado por la exquisitez literaria, el gusto estético y el acceso a una profusa documentación de carácter histórico.

La obra está estructurada en once capítulos. Mientras que el primero de ellos, "Antecedentes familiares", se centra en exponer los precedentes musicales más lejanos de Espeita García-Arista, el segundo capítulo, "José Espeita Fontán en la Barcelona musical” se centra en la presentación del progrenitor del protagonista del trabajo a través del ambiente musical y artístico que lo rodeó y que lo convirtieron en uno de los interlocutores más visibles de un espacio musical de primer orden, relacionado con algunas de las principales figuras de su época, como Hipólito Lázaro (1887-1974), Marcos Redondo (1893-1976) o Pablo Sorozábal (1897-1988), entre otro muchos.

Ya el tercer capítulo, titulado "La infancia de José Espeita García-Arista”, es cuando la investigación se focaliza en los primeros años vitales del músico para, en el capítulo 4, "Estudios de música y peritaje mercantil", presentar sus múltiples inquietudes y preocupaciones artísticas y vitales, lo que determinó que estudiara música -comenzando su 
carrera en el Conservatorio Oficial del Liceo de Barcelona bajo la dirección, entre otros, de Zamacois, Barberá y Anglés-, y que también realizara estudios en peritaje mercantil. Sin embargo, tal como su autora expone posteriormente, finalmente Espeita García-Arista decide dedicarse por completo a su vocación artística, de ahí la ampliación de sus estudios musicales en el Conservatorio Superior del Liceo, de forma paralela a su incursión en el mundo laborar a través de la realización de actuaciones en la Bodega Andaluza del Hotel Colón de la ciudad condal.

Por su parte, el capítulo 5, "Guerra civil española, 1936-1939", muestra una faceta más humana e histórica del protagonista del volumen, en una Barcelona destrozada, mientras el sexto capítulo, titulado "Los difíciles años 40", presentan a un músico que, en lo profesional, se abre campo en facetas musicales muy diversas -que quiso desarrollar incluso en Venezuela, donde planeó trasladarse pero cuyo viaje, finalmente, no pudo realizarse al no lograr los permiosos necesarios debido al control de la emigración- y en lo personal comienza una nueva etapa vital con Vicenta Ramisa Torrens, su esposa, con quien forma una familia en la que la música también ocupó un lugar muy significativo.

Ya en el capítulo 7, "Los años 50, dedicación plena musical", se aborda la consolidación de su carrera, con una dedicación musical plena, con especial mención a su trabajo como pianista acompañante y como pianista de orquestas, destacando su labor en la orquesta Copey. Conviene apuntar que la autora también presenta a Espeita García-Arista como músico de canciones -algunas firmadas por pseudónico Vitey-, colaborando con diversos letristas y dando como resultado temas tan célebres como "Soy un charro mejicano", sin olvidar las composiciones para ballet en colaboración con Sacha Goudine, bailarín y coreógrafo de Georgia. Esta oscilación entre la composición urbana y la composición de concierto no solo es un signo distintivo de las inquietudes y de la labor heterogénea de Espeita García-Arista, sino también un reflejo de la necesidad, por parte de los músicos de la época, de abordar diferentes ámbitos para mantener ecoómicamente a sus familias.

En el octavo capítulo, "Inicio del teatro musical en Radio Barcelona E.A.J. 1", se habla de la labor de Espeita García-Arista como maestro acompañante en la mencionada emisora, componiendo obras musicales literarias interpretadas a través de las ondas, como Mujercitas (1958) o Canciones para ti (1955). El género escénico, incluso infantil, también es abordado por parte de nuestro protagonista en esta época, destacando su obra El valiente Roberto, así como ballets y otras obras para radioteatro.

En el capítulo 9, que lleva por título "Reflexiones y nuevas creaciones de un compositor", se profundiza en la labor literaria del músico, autor de crónicas musicales para la revista cultural Plaza Cataluña desde el año 1962. Especialmente destacan sus reflexiones sobre Debussy, sobre la reaparición en el Palacio de la Música de Cziffra en 1962 y sobre Stravinsky, lo que incide en su parte más reflexiva y muestra a un músico también dedicado a la faceta más intelectual y literaria, consciente de la relevancia de esos hechos y autores en la realidad del momento. Paralelamente a la escritura, Espeita GarcíaArista continúa su trabajo como compositor de música de concierto, destacando en esta época su Sonata israelita para piano. El capítulo también ilustra su intensa labor como autor de comedias musicales y de canciones, ésta última desarrollada de forma intensa durante los 
años sesenta y setenta, en cuyo legado destacan especialmente las colaboraciones con Luis Lucena (1932), con quien, entre otros temas, compuso "Españolear" (1966), una canción que no solo logró un gran éxito sino que fue el tema principal de la película homónima.

En el capítulo 10, "Banda sonoras de cine", se habla de su vinculación al medio audiovisual, un contexto en el que se introduce a mediados de los años sesenta y donde trabaja hasta la década de ochenta. Al igual que para otros músicos de su época, el cine significaba un favorable modo de sustento económico y también un terreno de experimentación gracias a la unión de diferentes disciplinas artísticas. Especialmente, y aunque trabajó para varias productoras, la autora destaca la colaboración de Espeita GarcíaArista para Producciones Cinematográficas Balcázar, haciéndose cargo de la música de películas como El misterio de la vida, Inés de Villalonga o Las juergas del señorito, entre otras.

Finalmente, el capítulo 11, "Últimas composiciones musicales", da testimonio de una vida dedicada a la música hasta sus últimos días, pues, durante sus dos últimas décadas, su compromiso con la música continuó siendo su signo distintivo. Sin abandonar la docencia como profesor de composición, armonía, canto y solfeo, se ocupó de la dirección del Coro del Hogar de Pensionistas de Bach de la Roda de Barcelona, entroncando, en parte, con con el espíritu de la Casa di Riposo per Musicisti fundada por Giuseppe Verdi (1813-1901) en Milán, formado por personas mayores con cierta educación musical. José Espeita García-Arista continuó escribiendo hasta el final de sus días, como constatan su Rapsodia asturiana para piano y la que se considera su última gran obra Lacras, una ópera en dos actos.

Tras el undécimo capítulo se incluye un árbol genealógico, que clarifica las relaciones personales y familiares del protagonista -especialmente complejas por la abundancia de referencias en los capítulos primero y segundo-, y éste es continuado por una útil cronología vital y musical de Espeita García-Arista. Cierran el volumen la profusa bibliografía y un apéndice fotográfico que permite poner cara a un músico presentado en su faceta más humana y musical a través de este ejemplar.

El libro demuestra un profundo conocimiento sobre la historia y la cultura en Barcelona por parte de la autora que resultará de interés, sin duda, no solo a músicos o musicólogos, sino también a todos aquellos interesados saber más de la historia contemporánea. Por todo lo mencionado, se trata de una obra en la que se expone, de forma excelente, el ambiente y los interlocutores de la realidad cultural de la Cataluña de finales del siglo XIX y de todo el siglo XX a partir de uno de sus músicos más relevantes de su tiempo, José Espeita García-Arista.

\section{Virginia Sánchez Rodríguez}

Universidad de Castilla-La Mancha

ORCID iD: http://orcid.org/0000-0001-8071-2937 